Адрес статьи / To link this article: http://cat.ifmo.ru/ru/2017/v2-i4/124

\title{
Цифровые технологии как инструмент реконструкции театрального события
}

\author{
О.А. Чепурова \\ ФГБУК «Российский государственный академический театр драмы \\ им. А.С. Пушкина (Александринский)», Россия \\ olga.chepurova@gmail.com
}

\begin{abstract}
Аннотация. «Текст» спектакля - сложновоспроизводимая материя, буквальная «запись» которой невозможна. Реконструкция исторического спектакля, который не был зафиксирован ни на один из современных мультимедиа носителей - задача еще более сложная. Однако в данной статье описан опыт реализации проекта по воссозданию спектакля 1896 г. «Чайка». В работе представлена методика создания прототипа спектакля с помощью оцифровки исторических материальных и нематериальных артефактов, причастных к этой знаменитой постановке.
\end{abstract}

Ключевые слова: театр, наследие, мультимедиа, цифровые технологии, история, реконструкция, театральное событие

\section{1. Введение}

Банальностью будет говорить о том, что цифровые технологии на сегодняшний день играют решающую роль в создании продукта визуального искусства. Театр, как наиболее синтетический его вид, естественно, ими не пренебрегает. Он вбирает в себя все, что может обогатить воплощение образного ряда, задуманного постановщиком. Однако меняют ли технологии сущность театрального искусства? Это вопрос, однозначного ответа на который не существует.

Один из наиболее авторитетных исследователей так называемого «цифрового спектакля», Стив Диксон отмечает: «Обозреватели нового медиа часто принимают полярные позиции, говоря о компьютерных технологиях либо как о революционных и провозглашающих новые парадигмы, либо как о новой одежде императора, прикрывающей старые техники и модели. Это критическое разделение зависит от разных отношений и перспектив, определяемых культурой и идеологией. Ощущение “новизны” компьютерных технологий наиболее ярко, когда они воспринимаются в контексте инструментов для значительных социальных, культурных и художественных изменений. В этом плане они видятся генераторами настоящей переоценки и переосмысления моделей художественных и коммуникационных техник и парадигм. Но когда компьютерные технологии рассматриваются спокойно, в соотношении с более старыми коммуникационными средствами и художественными формами, то становится легко провести близкие параллели и 
аргументировать противоположное» [1, с. 7]. Театр, будучи искусством, которое существует «здесь и сейчас» однозначно является инструментом социальных и художественных изменений. Он как зеркало отражает реалии настоящего, стимулируя к рефлексии и переоценке ценностей. Не чужды ему и исторические художественные формы, как одной их старейших форм искусства.

Проект «Реконструкция театрального события - спектакля «Чайка» на Александринской сцене 1896 г.», инициированный в 2015 г. совместными усилиями Новой сцены Александринского театра, Российским Институтом сценических искусств и Университетом ИТМО, стал своеобразным ответом на размышления Стива Диксона. Идея заключалась в том, чтобы воссоздать на основании сохранившихся материальных и нематериальных артефактов прообраз того, как выглядела самая первая постановка широко известной пьесы А.П. Чехова. Базой для реализации проекта стало исследования проекта стало исследование А.А. Чепурова, посвященное спектаклю «Чайка» [2], дополненное в ходе работы над проектом.

Авторы проекта предположили, что цифровая технология может быть использована не только для создания оригинального контента современного театрального события, но она так же может стать инструментом для переведения исторических документов в цифровую реальность. Таким образом, материальная документация спектакля становится предметом для создания цифрового прототипа исторического события. Дискретная информация, сохранившаяся в архивных документах, описаниях, эскизах и немногочисленных фотографиях, благодаря цифровым технологиям была синтезирована и представлена в виде покартинной визуализации сцен из спектакля.

Естественный вопрос, который встал перед рабочей группой, был связан с эмоциональным содержанием воссоздаваемого театрального события. В этом отношении группа исследователей предпочла пойти по пути деперсонализации события, не нагружая его эмоциональным аспектом. Это подразумевало, что реплики актеров были даны в форме субтитров, а прочий звуковой ряд подразумевал лишь знакомство с оригинальным музыкальным сопровождением, использованным в спектакле.

\section{2. Разработка методики реконструкции театрального спектакля}

Театральное произведение исчезает как текст ровно тогда, когда опускается занавес и прекращается действие. Тем не менее, театральные тексты оставляют определенные следы, материальные артефакты, такие как: изобразительные материалы (фотографии, картины), фонограммы, литературные описания (рецензии, воспоминания, письма), технические документы. На их основе благодаря привлечению цифровых технологий, оказалось возможным воссоздать прообраз события, со свойственной ему структурой, действенной композицией, динамическими параметры.

До сих пор история театра строилась таким образом, что мы изучали только отражения театральных произведений: театральную критику, мемуары, изображения театральных сцен, но не изучали сам сценический текст. Каким же образом можно восстановить и реконструировать то, чего нет на материальных носителях? Как воссоздать образ исторического спектакля, не запечатленного ни на фото, ни на видео носителе?

В свое время проблемой реконструкции театральных текстов занялись немецкие ученые, в частности немецкий медиевист Макс Герман. Впоследствии в Петербурге (Ленинграде) так называемая «гвоздевская школа» развивала и продолжала традиции, заложенные немецкими исследователями театра. Но если в 30-е годы не существовало еще достаточно технологических средств для решения этой задачи в динамическом ключе, то современные цифровые технологии дают нам эту возможным.

В петербургской театральной библиотеке в собрании Русской драмы сохранился ряд документальных свидетельств, связанных с постановкой чеховской «Чайки». И, в первую очередь, сохранился сценический экземпляр пьесы с постановочными пометками режиссёра (рис. 1). Именно он явился для группы одним из основных источников реконструкции сценического текста. Слой текста, написанный поверх авторского, чеховского текста, позволил исследовать и реконструировать мизансцены спектакля, сцена за сценой. Однако для того, чтобы эти мизансцены, написанные и зафиксированные режиссером в авторском экземпляре представить

International Culture \& Technology Studies, Vol. 2, No. 4 
визуально, в развитии, необходимо, было, в первую очередь, смоделировать сценическое пространство. Совместно с коллегами из ИТМО, была разработана стратегия реконструкции декорационного решения этого спектакля. Для этого была изучена система оформления театральной сцены в 1890-х годах. Тогда было принято решение монтировать спектакль из имеющихся декорационных модулей, так называемых «типовых декораций». Одна и та же типовая декорация, будучи модернизирована в соответствии с режиссерскими пометками и авторскими ремарками, приобретала совершенно новый вид в том или ином спектакле. Таким образом, театральное оформление представляло собой своеобразные модификации одних и тех же модулей. Изобретательность постановщика состояла в том, чтобы из этих элементов создавать совершенно разные картины.

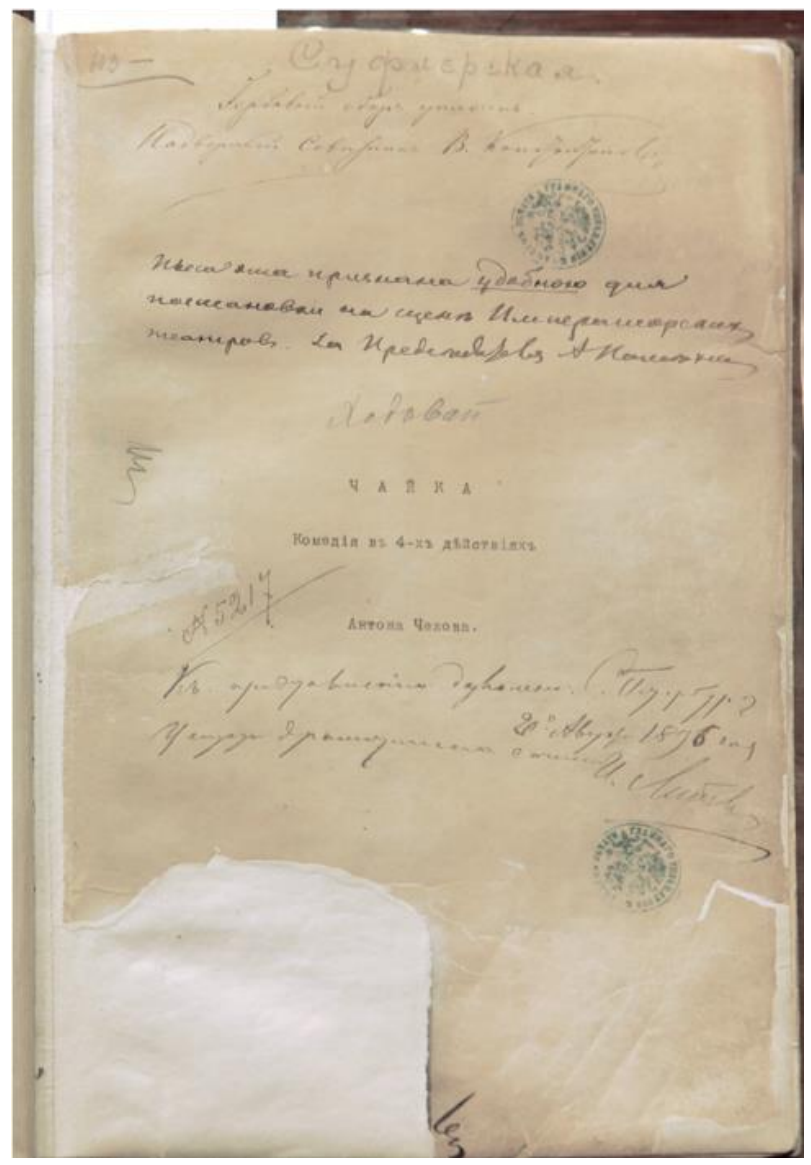

Рис. 1. Страница сценического экземпляра пьесы с постановочными пометками режиссёра

В Российском государственном историческом архиве сохранились так называемые «монтировки» спектакля. В фонде №497 от 1896 г. хранится монтировка чеховской «Чайки». Изучив ее, мы можем представить, каким именно образом режиссер располагает существующие типовые модули в пространстве сцены (рис. 2). Эти данные должны быть сопоставлены с еще одним документом - «Описью декораций и мелочей Александринского театра 1890-е гг.». Здесь представлены те декорационные модули, из которых режиссер-монтировщик создавал спектакль. Здесь указаны практически все художники, кто писал и какие наборы декораций. В Театральном музее были найдены эскизы, которые можно было привязать к описям декораций. Таким образом, был выявлен иконографический материал, на основе которого были сделаны декорации, из которых составлялись монтировки пьес, что позволило сконструировать мизансценический текст в мельчайших деталях. В условиях отсутствия точной информации о цветовом решении интерьера был использован алгоритм нейросетей, позволивший определить колористику интерьера по чернобелой фотографии. Это позволило сформировать полноценный визуальный образ спектакля, возможность ощутить то настроение, которое создавалось режиссером на сцене (рис. 3). 

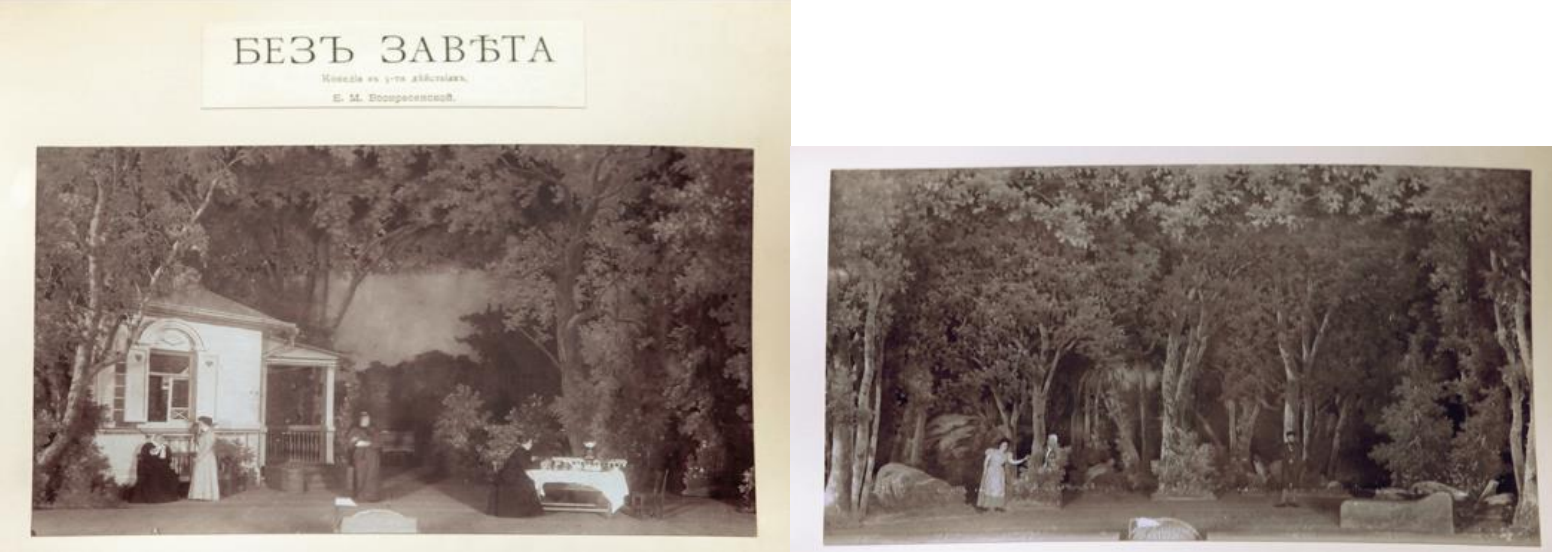

Рис. 2. Эскизы типовых декораций
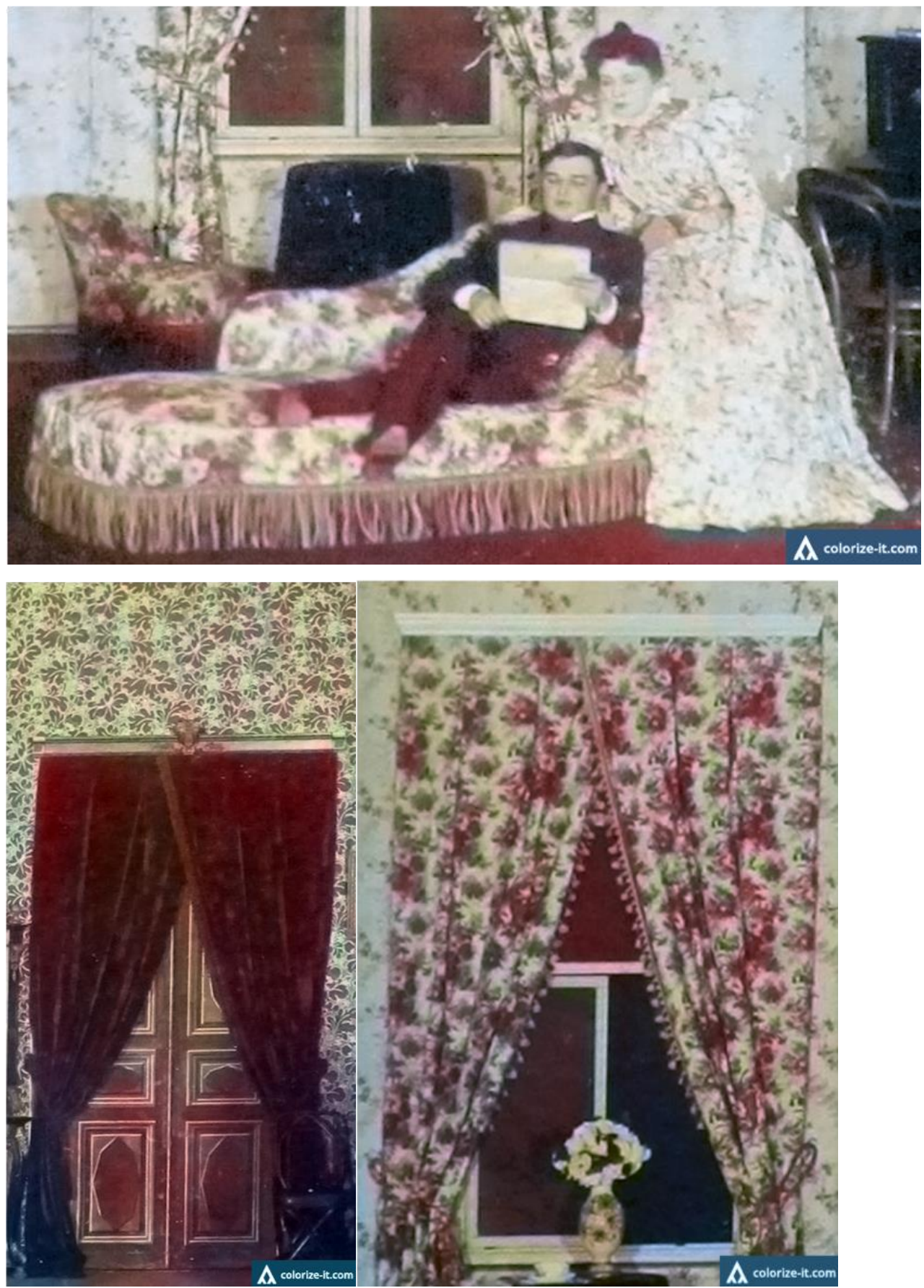

Рис. 3. Фотографии интерьеров, обработанные в редакторе восстановления цвета

International Culture \& Technology Studies, Vol. 2, No. 4 
К сожалению, не сохранилось фотографий артистов в ролях в постановке «Чайки» 1896 г. Однако смоделировать как выглядели актеры оказалось тоже возможно. Сохранилось большинство актерских портретов тех, кто принимал участие в постановке (рис. 4). Что касается костюмов, то в монтировке сохранились подробные описания того, во что были одеты артисты в той или иной сцене. В спектакле актеры в значительной мере использовали «свой гардероб». На основе аналогичных фотографий актеров, в костюмах из современной пьесы, то мы смогли довольно достоверно представить, каким образом были одеты и загримированы персонажи чеховской «Чайки».
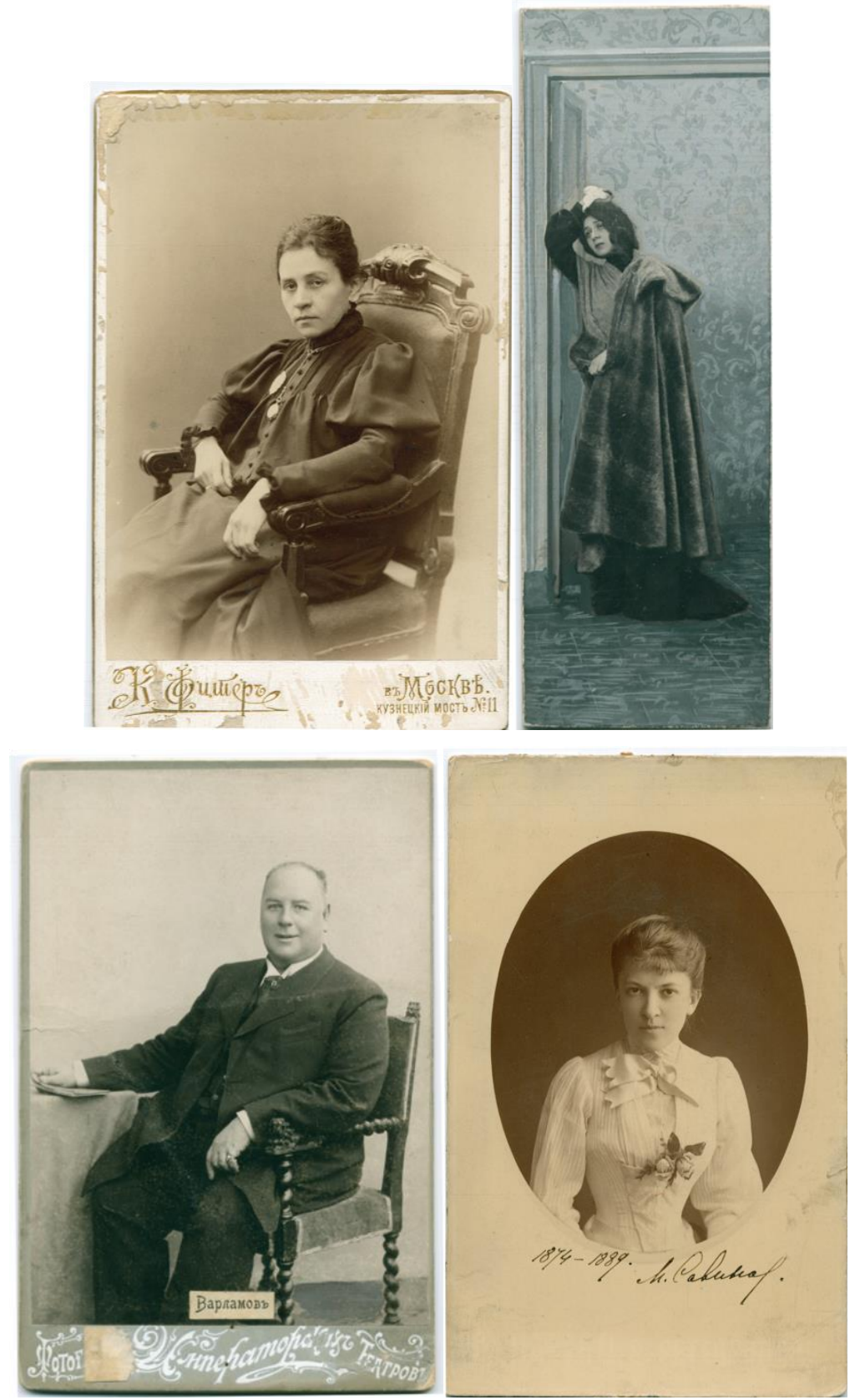

Рис. 4. Фотографии актёров

В фондах музея Александринского театра и Санкт-петербургской государственной театральной библиотеки были найдены фотографии артистов в жизни. Для каждой персоналии было отобрано до десяти фотографий в разных костюмах. Особенности костюмов каждого персонажа были выявлены на основе авторских ремарок Чехова и сведений, имеющихся в костюмной монтировке спектакля. Художник-дизайнер проекта отрисовал фигуры всех персонажей поактно (рис. 5), а затем, на основе анализа мизансцен спектакля, зафиксированных в режиссерском экземпляре пьесы (пометки режиссера Карпова и ремарки), был составлен перечень 
положений каждого персонажа по ходу движения действия и база изобразительных материалов дополнена.

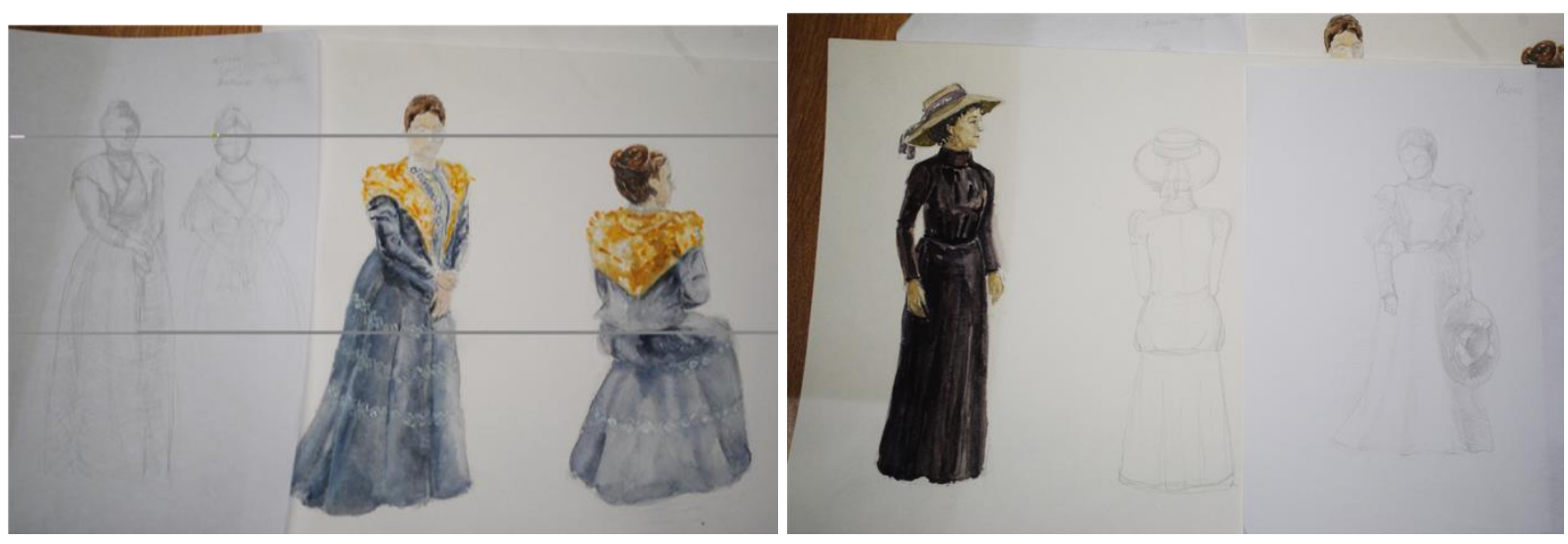

Рис. 5. Эскизы фигур актёров в костюмах

Как выяснилось, в монтировке была представлена цветовая драматургия костюмов. И когда исследовательская группа «одела» смоделированные фигурки актеров в костюмы соответствующих цветов, то стало понятно, как режиссер манипулировал цветовой гаммой, располагая артистов в различных мизансценах. Например, когда Нина выходит справа в белом платье, Маша появляется слева в черном платье. То есть появляются цветовые антиподы, которые формируют контраст, что создает характер напряженного сопоставления друг с другом.

\section{3. Принцип структурирования контента}

Структурирование контента реализовывалось в соответствии с поставленной задачей системной реконструкции спектакля, предполагавшей покадровое воссоздание действия, происходящего на сцене (рис. 6). Это предполагало конструирование декорационного оформления, воссоздание исторических мизансцен, перемещений персонажей «на реплики» и в соответствии с документальными записями, приведенными не только в тексте пьесы, но, главным образом, в сценическом экземпляре Е.П. Карпова.

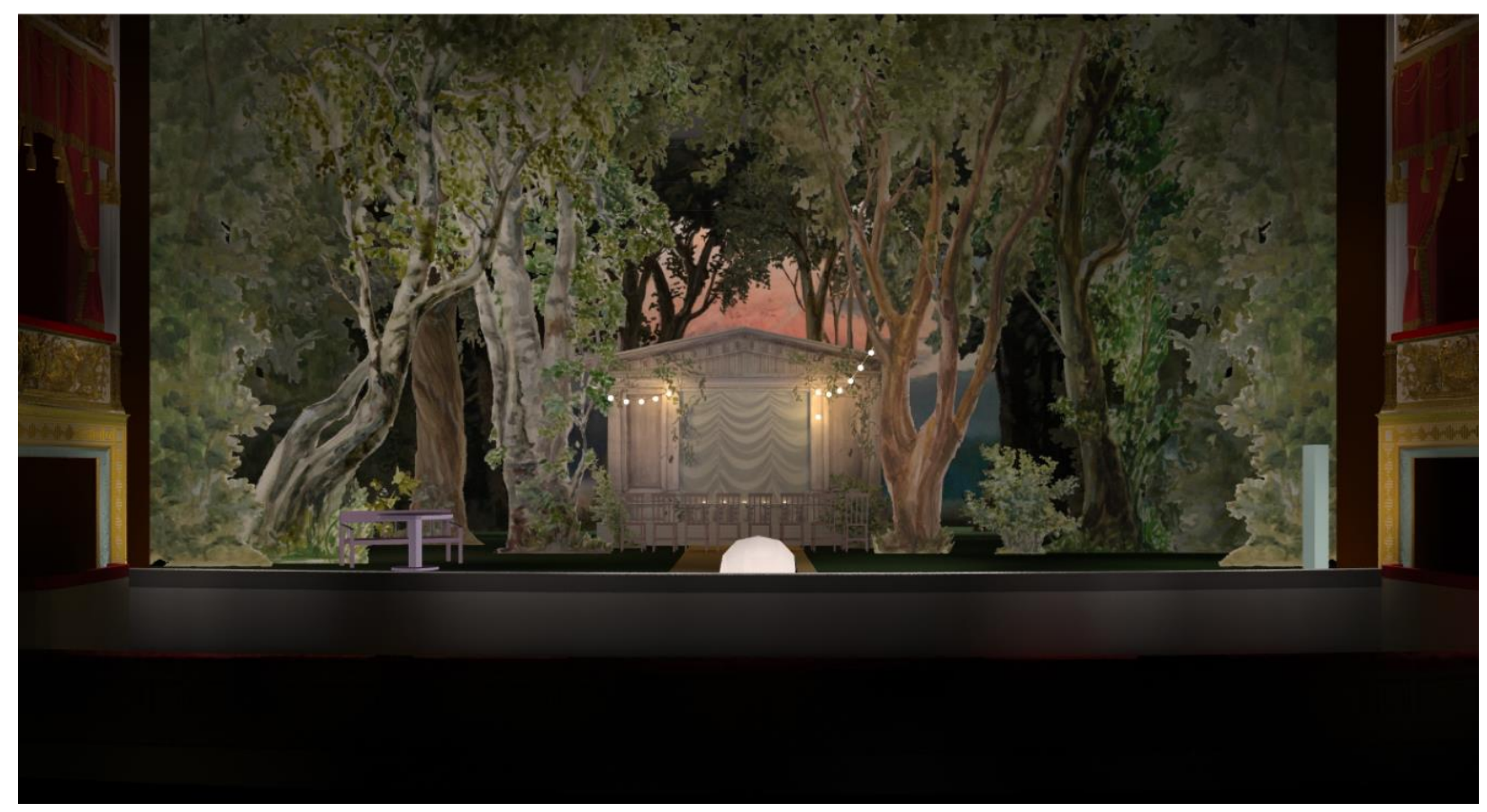

Рис. 6. Пример скрин-шота восстановленной сцены

Так, например, в ходе исследование было определено, что с наибольшей степенью вероятности, в 3-ем акте сцена представляла собой павильон, отделанный салатными обоями с 
желтыми цветами. Модули этой декорации, зафиксированные в разных позициях на различных фотографиях, были расположены в трехмерной виртуальной модели в соответствии со схемойчертежом, имеющимся в тексте сценического экземпляра пьесы. Данный чертеж был сделан помощником режиссера Е.П. Карпова во время репетиций. Двери, окна, предметы мебели и бутафории были расставлены в соответствии данным чертежом. Получившаяся модель была в деталях отрисована художником-дизайнером с проработкой предполагаемых фактур. Фактуры, цвет и форма предметов были сопоставлены с сохранившимися в фонде музея Александринского театра подлинными предметами на основе альбома мебели и бутафории.

Таким образом, оформление сцены 3-го акта было смоделировано в объеме и помещено в имеющуюся трехмерную модель сцены Александринского театра, созданную в масштабе, соответствующем реальным параметрам сцены [3]. На основе архивных документов, которыми располагала креативная группа, и учитывая схему расположения осветительных приборов на сцене Александринского театра в 1890-е годы (РГИА, Фонд 497, опись 14), было смоделировано художественное освещение декорации, соответствующее авторским ремаркам драматурга А.П. Чехова и указаниям режиссера Е.П. Карпова, зафиксированным в сценическом экземпляре пьесы. В ходе работы было выявлено, что схема освещения являлась типовой для представления на сцене эпизодов, происходящих в дневное время в интерьере комнаты (павильона). Система освещения основывалась на лампах, размещенных в рампе сценической площадки (без применения цветных светофильтров), а также на использовании боковых кулисных софитов. Освещение задника, изображающего пейзаж за окнами, было произведено с помощью специальных софитов, установленных позади основной декорации. При этом софиты, укрепленные на падугах, не использовались.

\section{4. Выстраивание траекторий перемещения персонажей}

Выстраивание траекторий перемещений персонажей связано с воссозданием мизансцен спектакля. Следуя режиссерским указаниям, зафиксированным в сценическом экземпляре Е.П. Карпова, а также руководствуясь оригинальными ремарками, имеющимися в тексте А.П. Чехова, каждый из воссоздаваемых актов был разбит на кадры, соответствующие изменениям положений артистов на сцене, начиная от перемещений по игровой площадке и заканчивая изменениями поз. На основе избранного принципа 3-й акт был разбит на 93 кадра, а 4-й акт на 135 кадров.

\section{5. Результаты применения цифровых технологий как инструмента реконструкции театрального события}

Результатом работы над проектом стало создание универсальной методики, с помощь которой на основе документальных источников, фиксирующих процесс подготовки и проката театрального спектакля, реконструируется художественный образ спектакля в его специфических особенностях (развитие сценического действия в трехмерном пространстве). Данная методика позволяет реконструировать как исторические театральные тексты, способствуя тем самым сохранению и изучению исторического наследия мирового театра, так и фиксации современных сценических партитур, позволяющих закрепить авторское право режиссера на сценическое произведение.

Таким образом, становится очевидным, что хранящиеся в архивах и библиотеках документальные свидетельства о театре прошлых лет могут быть не просто самоценными документами, а элементами действенной реконструкции исторических сценических текстов. Они позволяют реинкорнировать театральное искусство ушедших эпох с помощью цифровых технологий, позволивших свести все части воедино.

\section{Литература}

[1] Dixon, St. Digital Performance: A History of New Media in Theatre, Dance, Performance Art, and Installation. The MIT Press, 2007. -832 p.

[2] Чепуров А. А. Александринская "Чайка : [посвящена первой постановке пьесы А.П. Чехова "Чайка"] / А.А. Чепуров ; Рос. гос. акад. театр драмы им. А.С. Пушкина (Александр. театр), С.-Петерб. театр. альм. "Балт. сезоны". - СПб. : Альм. "Балт. сезоны", 2002. - 351 с. 
[3] Борисов, Н.В. Мультимедиа-реконструкция театрального события. Премьера спектакля «Чайка» на Александринской сцене 17 октября 1896 г. [электронный текст] / Борисов, Н.В., Никитин, А.В., Смолин, А.А., Трушин, В.А., Чепуров, А.А., Чепурова, О.А. // Культура и технологии. 2016. Том 1. Вып. 1. С. 1523. URL: http://cat.ifmo.ru/ru/2016/v1-i1/65 (дата обращения: 8.10.2017)

\title{
Digital Technology as a Tool of a Reconstruction of Theatrical Event
}

O.A. Chepurova

Alexandrinsky Theater, Russia

\begin{abstract}
The "text" of the performance is a complexly reproducible matter, the literal "recording" of which is impossible. The reconstruction of the historical performance, which was not fixed to any of the modern multimedia carriers, is an even more difficult task. However, this article describes the experience of a project to recreate the play in 1896 "The Seagull". The paper presents a technique for creating a prototype of a performance by digitizing historical material and intangible artifacts involved in this famous production.
\end{abstract}

Keywords: theater, heritage, multimedia, digital technologies, history, reconstruction, theatrical event

\section{References}

[1] Dixon, St. Digital Performance: A History of New Media in Theatre, Dance, Performance Art, and Installation. The MIT Press, 2007. - 832 p.

[2] Chepurov A.A. Aleksandrinskaja "Chajka : [posvjashhena pervoj postanovke p'esy A.P. Chehova "Chajka"] / A.A. Chepurov ; Ros. gos. akad. teatr dramy im. A.S. Pushkina (Aleksandr. teatr), S.-Peterb. teatr. al'm. "Balt. sezony". - SPb. : Al'm. "Balt. sezony", 2002. - 351 s.

[3] Borisov, N.V. Mul'timedia-rekonstrukcija teatral'nogo sobytija. Prem'era spektaklja «Chajka» na Aleksandrinskoj scene 17 oktjabrja 1896 g. [jelektronnyj tekst] / Borisov, N.V., Nikitin, A.V., Smolin, A.A., Trushin, V.A., Chepurov, A.A., Chepurova, O.A. // Kul'tura i tehnologii. 2016. Tom 1. Vyp. 1. S. 15-23. URL: http://cat.ifmo.ru/ru/2016/v1-i1/65 (data obrashhenija: 8.10.2017) 